\title{
Hypophosphatemic rickets
}

INSERM

\section{Source}

INSERM. (1999). Orphanet: an online rare disease and orphan drug data base.

Hypophosphatemic rickets. ORPHA:437

Hypophosphatemic rickets is a group of genetic diseases characterized by

hypophosphatemia, rickets, and normal serum levels of calcium. 